\title{
Cross-border model of young personnel professional identity formation in Rostov region agro-industrial complex
}

\author{
Svetlana Murzina ${ }^{1, *}$ and Sergey Timofeev ${ }^{1}$ \\ ${ }^{1}$ Don State Technical University, 1, Gagarin sq., Rostov-on-Don, Russia
}

\begin{abstract}
The article is devoted to the study of statistical data on the number of students in the agro-industrial direction in the Rostov region, their demand in the labor market in the conditions of cross-border educational process. The transformation of the education system into a service sector makes self-identification with the profession more difficult. Changes also occur in the system of values and norms of new generations of professionals, whose professional identification formed in the transitive period of the educational space. The considered interdisciplinary approaches to the definition of identity revealed difficulties in the interpretation of this phenomenon in pedagogy, the variety of semantic approaches existed. All these changes lead to the development of a new adaptive model of behavior among students, lack of misunderstanding by educational actors of the essence of the ongoing reforms in the education field and, as a result, the emergence of ineffective educational institutions. If a person identifies himself within the profession that he engaged in, then the efficiency of work, its usefulness will be much higher. Identity as an aspect of motivation will help to remove professional tension, internal conflict. Based on the processing of statistical data, a hypothesis that they have a professional identity proposed. The authors of the article put forward proposals to improve the level of professional identity of young professionals on the base of cross-border model.
\end{abstract}

\section{Introduction}

Transnational or cross-border education refers to all types of higher education programs, or courses of study, or educational services, including distance education, in which students are located in a country other than the one where the University that confers the qualification is located. Programs may belong to the educational system of foreign country or be implemented independently of any national education system. The usefulness of such programs is better when students have high level of identity. In this field, the problem of identity considered from different points of view. Its study based on the tools of psychological, pedagogical, economic and sociological sciences.

The analysis of economic, psychological, pedagogical and sociological literature on the problem showed that representatives of various schools and directions were engaged in

\footnotetext{
* Corresponding author: merciana@inbox
} 
studying this issue. The problem of identity was considered in the context of social and personal characteristics [1, 2], through ideals and social norms [3, 4]. Certain aspects of the identity problem studied in the framework of the concept of T. Veblen [5], dedicated to the joint activity of individuals as professional agents. This term introduced into scientific use by Erickson, who first used it in his works. This concept considered from the point of view of psychology and as a psychological belonging to a particular social group or several groups at the same time. He considered the concept of identity as "a firmly internalized and personally accepted self-image in all the diversity of social relations" [1].

In the works of T. Parsons, identity explored through levels of solidarity. Parsons defined these levels as "the First level of solidarity reflects orientation in the whole system of actions in which a person is included. The second level is individual self-determination in the valuenormative space "[6,7]. When studying professional identity, it is important to identify levels of identification as a methodological basis. The expression of identity expressed through the value-normative attitudes at both the individual and professional levels. The purpose of the study was to identify the presence of professional identity of young personnel in the agroindustrial complex. For this purpose, it is necessary to identify the levels of identification as a methodological basis. Two types of identity taken as a basis: "1) conscious, when a person thinks about his behavior, is free to think about the goal and tactics of behavior, although he is not autonomous; 2) unconscious - a person unreflectably accepts the norms of behavior, habits, and rituals of the group" [8]. In order to understand the nature of professional pedagogical behavior of future young specialists, the conclusion of Mead [9] is especially important.

The Mead describes three forms of identity - language, game and multiplayer. These forms of intra-subject activity represented in professional activity: professional language is a means of self-expression and self-awareness through others. Play is the most effective way of role-based learning and involves performing multiple social roles at the same time. Collective play is carried out within the activities of professional collectives in the presence of normative solidarity" or, according to Mead [9], "the generalized other". V.A. Iadov et al. [10] paid much attention to the problem of identity crisis in Russian science. He gave such a definition of identity as "awareness, experience of belonging to a professional community" [10]. V.A. Iadov was more concerned with the problem of "we identity" using knowledge of sociology and psychology.

We are more interested in his approach to the study of behavior within professional groups. According to Iadov, the main social function of identification is the inclusion of the individual in the system of social relationships through communities and groups. Research has shown that professional identity should studied as a combined characteristic of various factors, it is the product of interdisciplinary interactions. Thus, identity can contribute to the motivation of professionals, increase their group cohesion within the professional group to which they belong. The professional identity of young employees of the agro-industrial complex can considered through inclusion in the group and assessment of their position as an insiders [11]. Depending on the place in the group, feelings can be multi-vector and depend on the degree of satisfaction of all categories of needs of the individual and his social status in society [12].

\section{Materials and methods}

The main methods for studying identity as a professional attitude and indicator of social mobility are:

- $\quad$ theoretical analysis of sources on the problem of economic identity research;

- $\quad$ methods of collecting empirical data; 
Based on the research, the results help to reveal the relationship between identity and professional productivity of an employee. Identity can contribute to the motivation of pedagogical agents, increase their group cohesion within the professional group to which they belong. To build the most accurate cross-border model of professional identity formation, you need to measure the level of identity by analyzing statistical data from Federal statistics service of Russian Federation (www.rosstat.gov.ru). According to statistics from the Ministry of agriculture of Russia, it is responsible for 10 research institutes, Rosrybolovstvo-16 research institutes, and Rosselkhoznadzor-3 research institutes. The total number of employees is 8.9 thousand people.

In addition, the Ministry of agriculture of Russia manages 54 universities, 23 institutions of vocational training, 146 small innovative enterprises and 30 experimental farms. The total number of research and teaching staff is 23 thousand people.

Based on statistical data, 194 agricultural research institutes, 5 independent experimental stations, and 160 Federal state unitary enterprises (pilot farms) can identified. The total number of employees is 25.4 thousand people.

In 29 higher education institutions under the jurisdiction of the Ministry of education and science of the Russian Federation, there are agricultural faculties where personnel trained in specialties and areas of agricultural profile. Students taught in 20 higher education institutions of the Ministry of education and science of Russia in the field of "nature management and water use", in 50 in the field of "land Management and cadastres". The system of agricultural education also includes 253 technical schools and colleges, which administered by 73 subjects of the Russian Federation.

Currently, students trained in higher education programs at higher education institutions of the Ministry of agriculture of Russia in 6 fields of knowledge, 25 enlarged groups of training areas and specialties, 63 bachelor's degree programs, 42 master's degree programs, and 10 specialties.

It is an important source of providing appropriate personnel for territories with a developed agricultural sector, taking into account the low employment rate of graduates of other educational organizations (faculties of classical universities, economic institutes, etc.) in rural areas.

The order for research in the interests of the industry formed in the form of a state task of the Ministry of agriculture of Russia to subordinate institutions and as part of the selection of promising innovative projects for grants from the Federal budget. The directions of current research are determine jointly by specialists of the relevant departments of the Ministry and scientists, taking into account the proposals of the agribusiness management bodies of the Russian regions.

According to Federal statistics service, there are currently 328,287 managers and specialists working in agricultural organizations in the Russian Federation, including 15,309 specialists in agronomic services, 12,715 animal technicians, 19,174 specialists in veterinary services, and 1,178 economists. Of the 24,698 heads of agricultural organizations, 16,592 $(67.2 \%)$ have higher education, 6,152 $(24.9 \%)$ have secondary vocational education, and $1,954(7.9 \%)$ have practical training. At the same time, $19.5 \%$ have an economic or managerial education, $22.8 \%$ have a non - core education, and $1.8 \%$ have an academic degree. In agricultural organizations, specialists with higher education -86093 people $(47 \%)$, with secondary professional - 79027 (43.2\%).

Moreover, the number of chief specialists with higher education is 34,920 (64.9\%), and with secondary professional education $-16,777$ (31.2\%).

The largest number of chief specialists with higher education is among chief economists $(79.5 \%)$ and chief agronomists $(76.9 \%)$, and the smallest number is among chief engineers $(60.2 \%)$, chief accountants $(61.9 \%)$ and chief power engineers $(47.5 \%)$. 
Agricultural education has certain features that distinguish it from the system of training highly qualified workers in other fields. E. N. Akhapkina and L. A. Krokhmal include the following specific features [13]:

$"$ the structure of the property complex of agricultural universities includes land plots and experimental fields, which are used in the educational process as the main means of transferring competencies, skills and knowledge;

- the structure of agricultural universities differs radically from the structure of classical universities in the presence of educational and experimental farms, veterinary clinics, seed production laboratories, animal vivarium, taxidermy laboratories and other specific units involved in the daily educational process;

departments of agricultural universities have their own branches located directly in agricultural enterprises, enterprises for processing agricultural products, forestry enterprises and are used as the main tool for practical training of students;

-the educational and material base of agricultural universities is specific and includes living organisms, which requires the availability of special infrastructure and additional labor costs for its maintenance, as well as for the maintenance of animals and other living organisms involved in the educational process;

- $\quad$ training in agricultural areas of training requires compliance with the principles of visibility, production of natural visual AIDS, their maintenance in a state that ensures the continuity and quality of the educational process. The maintenance of anatomical museums increases the complexity of the educational process, in addition, it is necessary to maintain an additional staff of auxiliary workers;

implementation of agricultural education services is possible only within the framework of an individual approach to training or training in small groups, since it is impossible to teach a future veterinarian to operate on an animal in a group of 30 people. Each student must be taught individually how to work with animals, plants, and other living organisms."

Currently, due to the implementation of the priority national project "development of the agro-industrial complex", innovative production technologies and modern machine systems being intensively introduced and effectively used in all sectors of the agro-industrial complex. This actualizes the contradiction between the requirements for a specialist on the part of agro-industrial production and the level of training of graduates of agricultural universities, and states that labor market participants need continuous improvement, updating, updating of knowledge, skills, and professional competencies. Professional competencies understood as integral professional characteristics that include a set of universal, general professional and professional competencies. Among the universal competencies in the current educational environment, the most relevant are the development of critical thinking in students, which contributes to the rapid search and analysis of a large amount of information from the global network, helps to solve pedagogical problems, and perform individual projects [14].

The formation of professional identity is possible if the latest scientific results integrated into the country's agricultural sector. This process will contribute to the sustainable professional cross-border development of specialists. This is possible if the following requirements met development of the latest structure of higher and additional professional agricultural education; updating and improving the scientific mainstream; availability of an effective model of interaction between agricultural educational institutions, business and the state; formation of a multi-level educational environment. 


\section{Results}

We analyzed and summarized data from the website of the Ministry of agriculture and food of the Rostov region don-agro.ru about the availability of vacancies and the number of offers of relevant specialties. Based on the results obtained, it can concluded that (see Fig. 1).

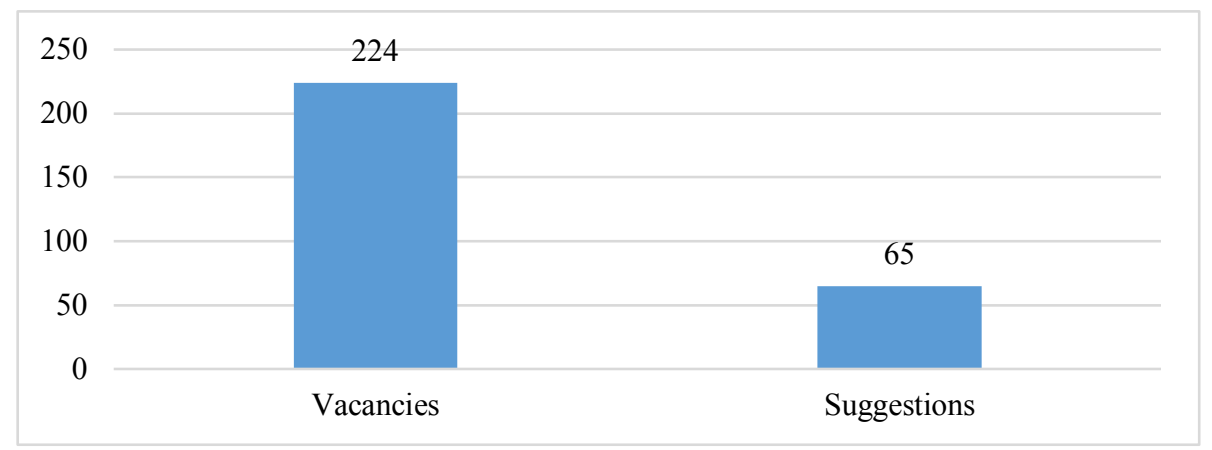

Fig. 1. The ratio of vacancies and the number of offers of the corresponding specialties, Source: www.don-agro.ru.

We have reviewed and researched materials on the number of graduates in the direction of training in the agricultural sector of DSTU (donstu.ru) and DSAU (dongau.ru). The data shown in Fig. 2.

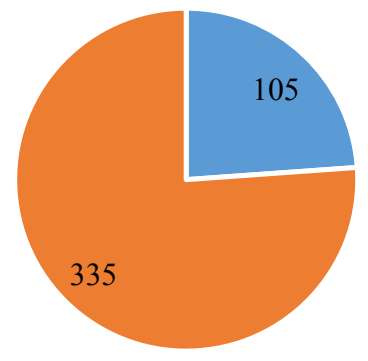

- DON STATE AGRARIAN UNIVERSITY

- DON STATE TECHNICAL UNIVERSITY

Fig. 2. The number of graduates of DSTU and DSAU, Source: www.don-agro.ru.

In 2019, 350000 and 360000 young specialists graduated from enlarged groups of specialties. We assume that based on the release of professional personnel in the agroindustrial sector in DSTU(335) and DSAU (105), the number of graduates should cover the demand for these professions in the labor market of the Rostov region. However, analysis of statistical data has shown that this is not the case. Based on these data, a number of reasons can identified:

- material dissatisfaction;

- mismatch of working conditions in the field and as a result the outflow of personnel to other territories;

- unwillingness to work in the specialty.

The first two reasons are external factors, and the third reason can be qualified as a lack of professional identity. This is our area of interest. In order to form a professional identity, you need to strengthen your motivation to learn. For young agribusiness professionals, this can done in the course of their training in the specialty, forming their insider behavior. 
The cross-border model of professional identity can used to overcome all difficulties. It based on some important principals (see Fig. 3).

The principle of variability implies flexibility and diversity of the content and forms of organization of training used in the system and allows for the most complete consideration of educational needs and opportunities. The principle of variation in education is associated with the possibility of flexible response to changes in the external environment and, as a result, the diversification of educational programs.

The principle of practical orientation of training, which assumes that the selection of training content focuses on the main directions of modernization of Russian education and the problems that arise in the process of their implementation. Practice orientation means focusing on the most popular areas of activity, choosing relevant professional tasks that are important for the implementation of the functions of a specific educational space (region, city, district, educational institution).

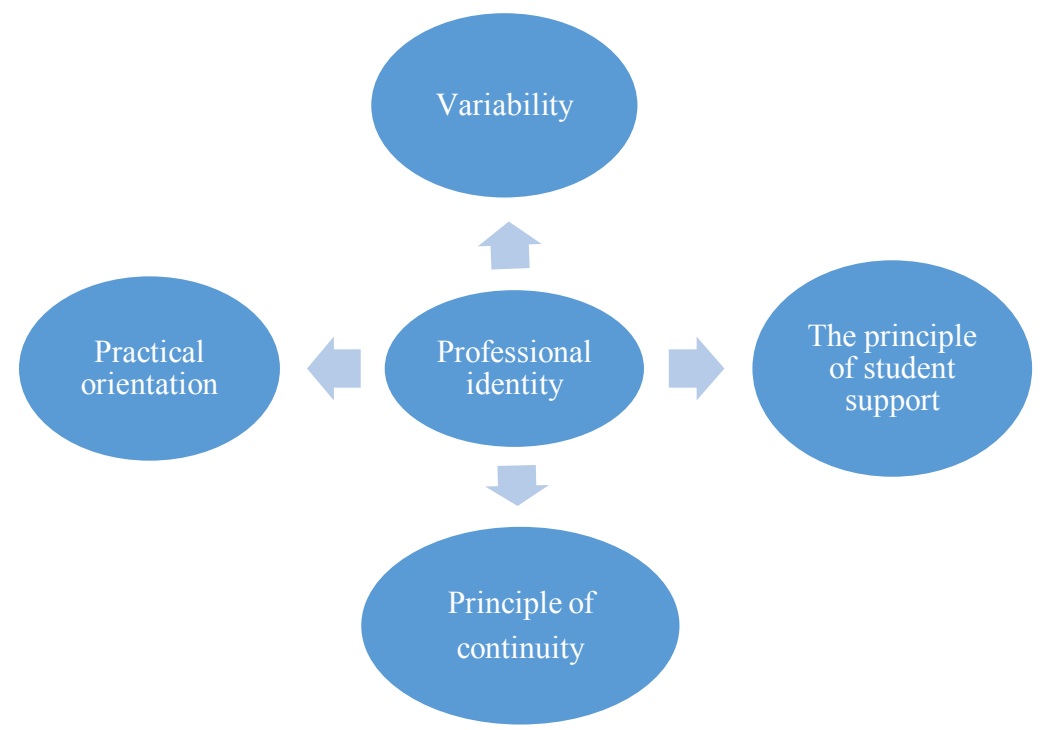

Fig. 3. Cross-border model of professional identity.

The principle of continuity of the educational process implies continuity between different educational programs and courses due to the modular and cumulative organization of the educational process and accounting for its results. Its essence consists in the interrelation and interdependence of goals, tasks, forms, methods, means and content of the system for forming the readiness of young professionals for self-development. It allows you to connect with practice, independent and research work.

Continuity is an objective necessary link between different stages and stages of development of a specialist in the conditions of continuous professional education. In the transition from one state of readiness to another, linking the present with the past and future, continuity determines the stability of the whole.

The principle of student support, which involves providing support and support for the selection of training programs necessary to improve the effectiveness of activities and the formation of their individual learning paths (determining the content, forms, methods, duration of training, etc.). Support provided by specially trained teachers-tutors who are capable of performing tutor support activities.

The principles developed within the framework of this model, aimed at the development of students, make it possible to form a professional identity and strengthen the insider behavior of future young professionals. Their relationship forms the integrity of the entire 
educational process, its consistency; structural content carried out from general to particular, taking into account the influence of all significant factors, as well as their interaction, the allocation of invariant and variable parts in the content.

\section{Discussion}

The modern agricultural sector requires qualitatively new personnel capable of being not only organizers and technologists of production, but also entrepreneurs who are fluent in the methodology of analysis and forecasting of economic activity, production management and marketing. Thus, the main direction of development of agricultural education is its compliance with the requirements of modern production. Training of agribusiness specialists should ensure needs of agriculture are met, have an advanced character, and serve as the basis for the development of professional schools as a system, bringing it in line with the nature of social needs.

The cross-border model develops the following features: 1) individual action (behavior), 2) creation of categories and norms of identity (non-compliance with them is regrettable), 3 ) choice of identity (status-role characteristic), 4) influence on others in the process of interaction [15]. We offer methodological recommendations on the selection of technologies in educational programs that allow students to form a professional identity. In our opinion, the main criteria indicating the high quality of programs should include:

- flexibility;

- mobility;

- $\quad$ possibility of individualization of training according to the program;

- competitiveness of the program in the market of educational order and services.

The flexibility of programs understood as the organization of its internal structure, which allows you to modify the program to meet the educational order, individual professional needs of students. The flexibility of the program must meet the rapidly changing requirements for professional training. The flexibility of the program makes it possible to adapt it to the educational needs and cognitive capabilities of students. The flexibility of the program also achieved due to the multi-functionality of the modules included in it. Modules provide a change in the educational process by modeling the applied learning technologies, teaching methods, or individual techniques aimed at solving the main didactic task in the context of changing competence characteristics. Polyfunctionality allows implementing the following functions: gnostic, monitoring, project-modeling, communication. Gnostic includes information and content, scientific and methodological support of educational needs of students, activation of innovative activities of all structural units of the complex. Monitoring - expert assessment of the effectiveness of professional development of competitive specialists, the formation of a professional management system. Project-modeling projectprogram target activity for modeling the education system. Communication defining the forms of education organization, technologically effective solutions, creating an innovative educational environment.

The mobility of the program consists in creating information networks, databases and banks of knowledge and digital data that allow the student to change regulate or supplement their educational program in the necessary direction. In the practice of professional education, the concept of academic mobility is used, which creates an opportunity for students to use the program, methodological, and material and technical resources of various educational institutions for professional development. This academic mobility achieved through the exchange of experience, the acquisition of opportunities that are not available for some reason within a single educational institution, overcoming the isolation of the system, and acquiring a European perspective. 
Individualization of training provided by the ability to build trajectories of professional development of students. Individualization involves taking into account the initial educational level and individual needs.

The essence of the competitiveness of programs as an educational service is their focus on providing training of a specialist of the level of professional competence that the consumer expects. Competitiveness is also determined through indicators of the availability and usefulness of educational services. At the same time, accessibility in the education system defined through the concept of "information accessibility", and usefulness-through the need to master this educational program for a specific consumer in connection with his professional request.

Determining the pedagogical grounds for selecting technologies, forms and methods of organizing the educational process should guide by the provisions of the activity approach. When implementing an activity-based learning system, the main thing is the optimal choice of technologies and teaching methods. To choose the best option among a variety of methods, you need guided by their compliance:

- $\quad$ laws and principles of training that follow from them;

- goals and objectives of the study;

- content and methods of this science in general and the educational program in particular;

- educational opportunities of students:

○ age-related (physical, mental);

○ the level of preparedness (educational and educational);

- features of the team (group) in which the training is conducted.

- $\quad$ features of external conditions (geographical, industrial, environmental);

- the capabilities of the teachers themselves: their previous experience, knowledge of typical situations in the learning process in which certain combinations of methods are most effective, their level of theoretical and practical training, their ability to apply certain methods and tools, their ability to choose the best option, personal qualities.

This algorithm quite generalized. In this regard, we can recommend its use not only for selecting methods, but also for determining the optimal educational technologies.

Choosing one or another technology with students need to keep in mind that the greatest effect of adoption can be achieved if we consider education, the implementation of which should be directed elected by the technology, the content that will present students with it, as well as the conditions in which it is used.

One of the urgent tasks of implementing the activity approach is to search for such technologies that can used to ensure the formation of a high level of development of professional competencies and the formation of professional identities. The achievement of these results seen with technologies in which the individual in the educational process is considered as a subject of activity, which itself determines the nature of this activity. The idea of using such technologies is that the training of any professional activity can successfully carried out by modeling the subject and social content of the upcoming activity in it. Today, a wide range of quasi-research and educational and professional technologies and methods that considered active used in practice. The effectiveness of their application can significantly increase if the potential of various groups of these methods in forming the level of professional competence of students taken into account. The resolution of this contradiction is possible only with fundamental changes in the processes and systems of agricultural education at all levels: socio-political, organizational-administrative and methodological. In other words, the training of future specialists should be prolonged and continue throughout life. 


\section{Conclusions}

Each profession has its own specific features that influence the formation of personality traits of the subject of labor in the process of its professional development. Objective working conditions, as well as self-perception in the profession, influence the generation of labor personality traits of the subject. Professional identity depends on the structure of the social sphere, which is exogenous in relation to it. Structure defined using organizational boundaries, and the functions reproduced by the individual used to combine social identities. Descriptions of identities may be contradictory, due to differences in social professional norms and values of young professionals.

The search for professional meaning based on the concept of employee identity. Each profession has its own specific features that influence the formation of personality traits of the subject of labor in the process of its professional development. In addition to objective working conditions, the generation of labor personality traits of the subject strongly influenced by its self-perception in the profession. [3] In the process of professional development of the individual as a subject of labor, it influenced by the specific features of labor activity, as well as the problem of self-identification. Readiness for innovation is now becoming one of the most important criteria of professionalism. One of the main goals of education is to train a qualified employee who is capable of effective work in the specialty at the level of world standards, ready for continuous professional growth, social and professional mobility. The essence of professional self-determination today is increasingly associated with helping a person find personal meanings in the chosen and mastered professional activity.

Education of specialists should not end with diploma, it should continue in production and with the involvement of specialists from research organizations engaged in finding solutions to current problems in the agro-industrial complex using innovative and modernized methods, including taking into account the experience of foreign colleagues.

Cross-border learning model based on the courses of additional vocational education, self-education and having the research skills of specialists must go to the professionalism of not only the employee, but also to serve as an indicator of innovativeness of the enterprise in which he works. Only an integrated approach to educational and industrial activities and the rejection of useless and unclaimed knowledge can form a closely interrelated system of "science-education-production", which can bring the agro-industrial complex of the Rostov region to a fundamentally new level of agricultural production in a short time.

In higher education reform, this phenomenon is especially relevant for changing the values and norms of new generations of specialists, whose professional identification realized in the space of destroyed values and norms.

Identity can promote collective action by motivating professional agents to participate in the affairs of the professional group to which they belong. The stronger the social connections in the community and the more stable the corresponding identity, the more resources can mobilized if necessary with minimal transaction costs.

Defining professional identity, it should considered as part of the product of economic self-consciousness, which is an economic, psychological and pedagogical category related to the result of determining a person's position in the system of professional relations, which is one of the basic ones.

The problem of professional identity research related to the need for a more in-depth analysis of factors that distort professional behavior. The problem of identity considered from different points of view. Approaches to its study based on the tools of psychological, pedagogical, economic and sociological sciences. Social identity depends on the structure of the social sphere, which is exogenous in relation to it. Structure defined using organizational boundaries, and the functions reproduced by the individual used to combine social identities. 
Descriptions of social identities may be contradictory, due to differences in social norms and values. Quasiprofessional activities for students can establish deep insider behavior and as the result professional identity. They involve simulation, game technologies and methods. Such as reflexive role-playing games, organizational and activity games, expert games, including computer games, the method of "reverse brainstorming", the method of "double brainstorming", the method of "conference of ideas», training on simulators, with the use of computer technology.

Relying on the activity approach in the content development allows solving the issues of mastering and developing the professional identity in the activity. The program should also provide for such forms and methods of working with students in which the assimilation of educational material takes place in conditions close to the conditions of its application. It should include practical independent work of students or in joint groups with the teacher, ensuring its problem-oriented nature.

\section{References}

1. E.H. Erikson, Childhood and society (WW Norton \& Company, New York, 1993)

2. S. Moscovici, European Journal Social Psychology 18, 211-250 (1998)

3. G.A. Akerlof, R.E. Kranton, American Economic Review Papers and Proceedings 98(2), 212-217 (2008)

4. J.B. Davis, Individuals and Identity in Economics (Cambridge University Press, New York, 2011)

5. T. Veblen, The Quarterly Journal of Economics 12(4), 373-397 (1898)

6. T. Parsons, Social structure \& person (Simon and Schuster, New York, 2010)

7. T. Parsons, Actor, situation and normative patterns: an essay in the theory of social action (LIT Verlag, Münster, 2010)

8. G.H. Mead, G.J. Biesta, D. Trohler, Philosophy of Education (Routledge, London, 2015)

9. G.H. Mead, H. Mind, Self and society (University of Chicago, Chicago, 1934)

10. N.I. Lapin, G.I. Osadchaia, V.A. Iadov, Russian Education and Society 45(9), 79-91 (2003) DOI: 10.2753/RES1060-9393450979

11. P.N. Ermakov, I.V. Abakumova, O. Fedotova, D.P. Shchetnina, Journal of Environmental and Science Education 11(18), 10829-10837 (2016)

12. S.J. Schwartz, An International Journal of Theory and Research 1(1), 7-58 (2001)

13. O.V. Beluzhenko, S.G. Kuren, S.I. Popov, N.S. Dontsov, XIII International Scientific and Practical Conference «State and Prospects for the Development of Agribusiness INTERAGROMASH 2020»: E3S Web of Conferences 175, 15017 (2020) doi.org/10.1051/e3sconf/202017515017

14. O. Fedotova, V. Latun, Y. Merinova, A Ertel, E3S Web of Conferences 175, 15026 (2020) DOI: $10.1051 /$ e3sconf/202017515026

15. E.V. Rudoy, PROBLEMS Professional education in the modern world 7(4), 1388-1400 (2017)

16. E.H. Erikson, Identity: Youth and Crisis (Norton, New York, 1968) 